\title{
Correlation Between Postoperative Hyperglycemia and the Occurrence of Surgical Site Infections After Surgery for Gastroenterological Malignancy: A Retrospective Analysis
}

Takehito Yamamoto ( $\nabla$ tkht26@me.com )

Kitano Hospital, The Tazuke Kofukai Medical Research Institute

Shugo Ueda

Kitano Hospital, The Tazuke Kofukai Medical Research Institute

Mami Yoshitomi

Hyogo Prefectural Amagasaki General Medical Center

Hiroaki Terajima

Kitano Hospital, The Tazuke Kofukai Medical Research Institute

\section{Research Article}

Keywords: surgical site infection, hyperglycemia, SSI, wound infection, Diabetes Mellitus

Posted Date: January 31st, 2022

DOI: https://doi.org/10.21203/rs.3.rs-1262504/v1

License: (1) (1) This work is licensed under a Creative Commons Attribution 4.0 International License.

Read Full License 


\section{Abstract}

Background. Surgical site infection (SSI) is one of the most important complications after surgery for gastroenterological malignancy in that it leads to prolonged postoperative hospital stay and increased inpatient cost. Especially in case for malignancy, SSI sometimes delays the initiation of postoperative treatments including adjuvant chemotherapy and that can negatively affect prognosis.

Methods. Patients with gastroenterological malignancy who underwent surgery in our institution were retrospectively reviewed and categorized according to the occurrence of incisional SSI; SSI group and no SSI group. The clinicopathological characteristics between two groups were compared, i.e. age, sex, body mass index, location of malignancy, results of postoperative blood examination, operation time, and amount of blood loss. Then, the same analysis was performed in the subpopulation that included colorectal cancer patients.

Results. The 528 patients enrolled in the present study consisted of 330 males and 198 females of mean age $68 \pm 11$ years at the time of their operation. The numbers of patients with diseases of the esophagus, stomach, small intestine, colon and rectum, liver, gallbladder, and pancreas were $25,150,7,255,51,5$, and 35, respectively. Open surgery was performed in 303 patients and laparoscopic surgery in 225 . Incisional SSI occurred in 46 patients (8.7\%). Univariate analysis showed that postoperative hyperglycemia (serum glucose level $\geq 139 \mathrm{mg} / \mathrm{dL}$ within $24 \mathrm{~h}$ of operation) was the sole significant risk factor for incisional SSI ( $p=0.026)$. Multivariate analysis showed that postoperative hyperglycemia was an independent risk factor for incisional SSI (odds ratio 1.89, 95\% confidence interval 1.009-3.614). In a subgroup analysis of patients who underwent colorectal surgery, the SSI occurred in 27 patients (10.5\%). It also showed that postoperative hyperglycemia was a significant risk factor for incisional SSI $(p=0.033)$, in addition to open surgery $(p=0.024)$.

Conclusions. Postoperative hyperglycemia was the independent risk factor for incisional SSI after surgery for gastroenterological malignancy. Prevention of postoperative hyperglycemia is important in achieving a decrease in the rate of incisional SSI.

\section{Background}

Surgical site infections (SSIs) are reported to be one of the largest contributors to overall inpatient cost [1-5]. Furthermore, especially for patients with gastroenterological malignancy, SSI sometimes leads to delayed initiation of postoperative treatments. Determining the risk factors for SSI could potentially improve intraoperative and postoperative wound management in patients at risk. Many papers have reported different preoperative, intraoperative, and postoperative risk factors for SSI in abdominal surgery [6-8], such as perioperative transfusion, cirrhosis, or anastomosis of the bowel. On the other hand, numerous studies have reported diabetic patients to be subject to postoperative infectious diseases including SSI [9-11]. Martin et al. analyzed the association between diabetes and the risk of SSI in their 
large systematic review and meta-analysis and reported the overall effect size for the association between diabetes and SSI as odds ratio (OR) 1.53 [9].

In diabetic patients, meticulous perioperative management of the serum glucose level can reduce the chance of SSI. We considered that the postoperative hyperglycemia, rather than diabetes mellitus itself, could be associated with SSI occurrence, while not only known diabetic patients but also unknown or non-diabetic patients could be at risk of postoperative hyperglycemia in some circumstances. In fact, Ata et al. revealed that a high serum glucose level was the only significant predictor of SSI for colorectal surgery patients [12].

The guidelines of the Centers for Disease Control and Prevention (CDC) divide SSI into three types: incisional, deep, and organ/space infections [13]. We considered that the risk factors and preventive measures for each of the three types differ. In the present study, we focused on incisional SSI and its risk factors in patients who underwent gastroenterological surgery for malignant diseases.

\section{Methods}

\section{Patients}

Patients with gastroenterological malignancy who underwent operations in our hospital were reviewed. Gastroenterological malignancy included malignant diseases (cancer, neuroendocrine tumor, and gastrointestinal stromal tumor as preoperative diagnosis) of the esophagus, stomach, small intestine, colon and rectum, liver, gallbladder, biliary duct, and pancreas. Based on the concept that SSI occurrence was associated with the operative procedure rather than the location of the disease itself, patients with disease of the distal biliary duct and papilla of Vater who received pancreatic resection were classified into "pancreas." We then divided the study patients into two groups, the SSI group and the no-SSI group, and compared clinical characteristics between them. Furthermore, we conducted the same comparison for the subgroup of patients with colorectal malignancy.

Patients with diabetes mellitus were defined as those who received pharmacological treatment for diabetes before the operation or those with a higher hemoglobin A1c level than normal. "Current smoker" was defined as an individual who smoked within 1 month before surgery.

\section{Diagnosis}

The patients with incisional SSI based on the definition of the guidelines of the CDC were included in the SSI group [14]. The wound was examined by a doctor and a nurse at least once a day until discharge of the patient from hospital. After discharge, the wound was examined by an outpatient doctor until 30 days after surgery. The diagnosis of SSI was made after discussions with surgeons, nurses, and members of the SSI surveillance team.

\section{Statistical analysis}


Continuous variables are presented as the mean \pm standard deviation, and categorical variables as number and percentage. The $\chi^{2}$ and Mann-Whitney $U$ tests were used to compare the two groups. Variables with associations with SSI in the univariate analyses (variables with $p$ value $\leq 0.1$ ) were included in the multivariate logistic regression model. The effect of the associations was expressed as the odds ratio (OR) and $95 \%$ confidence interval $(\mathrm{Cl})$. All statistical analyses were conducted by one of the physicians participating in the study (T.Y.) using JMP, version 10 (SAS Institute, Cary, NC, USA). All reported $p$ values are two-sided. A $p$ value of less than 0.05 was considered to indicate statistical significance.

Postoperative serum glucose level was determined as the level within $24 \mathrm{~h}$ of the operation. The cutoff value of the continuous variables was determined using the receiver-operating characteristic curve.

\section{Results}

A total of 528 patients were enrolled in the present study, after we excluded 17 patients whose data of postoperative blood examination within $24 \mathrm{~h}$ of operation were unavailable. Table 1 shows the clinical characteristics of all patients, consisting of 330 males and 198 females of mean age $68 \pm 11$ years at the time of surgery. The numbers of patients with cancer of the esophagus, stomach, small intestine, colon and rectum, liver, gallbladder, and pancreas were $25,150,7,255,51,5$, and 35 , respectively. Open surgery was performed for 303 patients and laparoscopic surgery for 225. Mean operation time was 327 minutes and the mean intraoperative blood loss was $348 \mathrm{~mL}$. Intraoperative blood transfusion was performed for 52 patients. 
Table 1

Clinical characteristics of all patients

\section{Variables}

Age (years)

Male

BMI (kg/m2)

Diabetes mellitus

Current smoker

Alb $(\mathrm{mg} / \mathrm{dl})$

Postoperative serum glucose

ASA classification

I

II

III

IV

Organ

Esophagus

Stomach

Intestine

Colon and Rectum

Liver

Gall bladder

Pancreas

Operative procedure

Open

Laparoscopic

Length of operation (minutes)

Blood loss (g)
Mean $\pm S D$ or $n(\%)$

$68 \pm 11$

$330(62.5)$

$22.6 \pm 3.7$

87 (16.5)

$51(9.7)$

$4.1 \pm 0.5$

$143 \pm 41$

$48(9.1)$

401 (75.9)

78 (14.8)

$1(0.2)$

$25(4.7)$

$150(28.4)$

7 (1.3)

255 (48.3)

$51(9.7)$

$5(9.5)$

$35(6.6)$

303 (57.4)

225 (42.6)

$327 \pm 161$

$348 \pm 490$

Data presented as mean \pm standard deviation or $\mathrm{n}(\%)$; BMI, body mass index; ASA, American Society of Anesthesiologists 


\section{Variables}

Intraoperative blood transfusion
Mean $\pm S D$ or $n(\%)$

$52(9.8)$

Data presented as mean \pm standard deviation or $\mathrm{n}(\%)$; BMl, body mass index; ASA, American Society of Anesthesiologists

Patient selection is shown in Fig. 1. Incisional SSI occurred in 46 patients (8.7\%). Table 2 shows the comparison between the SSI and no-SSI groups. Univariate analysis showed that postoperative hyperglycemia (serum glucose level $\geq 139 \mathrm{mg} / \mathrm{dl}$ within $24 \mathrm{~h}$ of operation) was the sole significant risk factor for incisional SSI ( $p=0.026)$. As shown in Table 3, multivariate analysis showed that postoperative hyperglycemia was an independent risk factor for SSI (OR 1.89, 95\% Cl 1.009-3.614, p=0.047). Diabetes mellitus itself was not associated with the occurrence of incisional SSI, nor with other factors (age, sex, body mass index, smoking, operative procure, etc.). 
Table 2

Comparison of clinical characteristics between SSI and no-SSI groups.

\begin{tabular}{|c|c|c|c|}
\hline Variables & SSI group & No-SSI group & $p$ value \\
\hline & $n=46$ & $n=482$ & \\
\hline Age (years) & $68 \pm 11$ & $68 \pm 11$ & 0.945 \\
\hline Male & $34(74)$ & $296(61)$ & 0.094 \\
\hline $\mathrm{BMI} \geq 25 \mathrm{~kg} / \mathrm{m} 2$ & $13(28)$ & $110(23)$ & 0.362 \\
\hline Diabetes mellitus & $9(20)$ & $78(16)$ & 0.555 \\
\hline Current smoker & $5(10)$ & $46(10)$ & 0.771 \\
\hline Alb (mg/dl) & $4.0 \pm 0.6$ & $4.1 \pm 0.5$ & 0.296 \\
\hline Postoperative hyperglycemia & $28(61)$ & $221(46)$ & $0.026^{\star}$ \\
\hline ASA classification $\geq$ III & $9(20)$ & $70(15)$ & 0.360 \\
\hline Organ & & & 0.100 \\
\hline Esophagus & $1(2)$ & $24(5)$ & \\
\hline Stomach & $6(13)$ & $144(30)$ & \\
\hline Intestine & 0 & $7(1)$ & \\
\hline Colon and Rectum & $27(59)$ & $228(47)$ & \\
\hline Liver & $5(11)$ & $46(10)$ & \\
\hline Gall bladder & $1(2)$ & $4(1)$ & \\
\hline Pancreas & $6(13)$ & $29(6)$ & \\
\hline Emergency surgery & $2(4)$ & $8(2)$ & 0.201 \\
\hline Operative procedure & & & 0.080 \\
\hline Open & $32(70)$ & $271(59)$ & \\
\hline Laparoscopic & $14(30)$ & $211(44)$ & \\
\hline Length of operation (minutes) & $352 \pm 199$ & $325 \pm 157$ & 0.824 \\
\hline Blood loss (g) & $389[0-1730]$ & 295 [0-1039] & 0.143 \\
\hline Intraoperative blood transfusion & $6(13)$ & $46(10)$ & 0.447 \\
\hline \multicolumn{4}{|l|}{${ }^{*} \mathrm{p}<0.05$} \\
\hline $\begin{array}{l}\text { Data presented as mean } \pm \text { standa } \\
\text { of Anesthesiologists }\end{array}$ & or n (\%); BMI, b & ass index; ASA, & an Society \\
\hline
\end{tabular}


Table 3

Multivariate logistic regression analysis of the risk factors of incisional SSI

\begin{tabular}{|llll|}
\hline Variables & Odds ratio & 95\% confidence interval & p value \\
\hline Male & 1.77 & $0.913-3.669$ & 0.092 \\
\hline Open surgery & 1.50 & $0.778-3.008$ & 0.231 \\
\hline Glucose $\geq 139$ & 1.89 & $1.009-3.614$ & $0.047^{\star}$ \\
\hline${ }^{*} \mathrm{p}<0.05$ & & & \\
\hline
\end{tabular}

In a subgroup analysis of patients who underwent colorectal surgery, the SSI occurred in 27 patients (10.5\%). Table 4 shows the comparison of the SSI and no-SSI patients. Univariate analysis revealed the same result of postoperative hyperglycemia as a significant risk factor for incisional SSI ( $p=0.033)$, in addition to open surgery $(p=0.024)$. 
Table 4

Comparison of clinical characteristics between SSI and no-SSI groups among patients who underwent colorectal surgery $(\mathrm{n}=255)$

\begin{tabular}{|c|c|c|c|}
\hline Variables & SSI group & No-SSI group & $\mathrm{p}$ value \\
\hline & $n=27$ & $\mathrm{n}=228$ & \\
\hline Age (years) & $67 \pm 12$ & $68 \pm 11$ & 0.446 \\
\hline Male/Female & 17 & 126 & 0.356 \\
\hline $\mathrm{BMI} \geq 25 \mathrm{~kg} / \mathrm{m} 2$ & 7 & 50 & 0.563 \\
\hline Diabetes mellitus & 6 & 26 & 0.109 \\
\hline Current smoker & 2 & 15 & 0.870 \\
\hline Alb (mg/dl) & $4.0 \pm 0.7$ & $4.1 \pm 0.5$ & 0.937 \\
\hline Postoperative hyperglycemia & 15 & 79 & $0.033^{*}$ \\
\hline ASA classification $\geq$ III & 3 & 39 & 0.427 \\
\hline Emergency surgery & 2 & 7 & 0.248 \\
\hline Operative procedure & & & $0.024 *$ \\
\hline Open & 13 & 62 & \\
\hline Laparoscopic & 14 & 166 & \\
\hline Length of operation (minutes) & $266 \pm 141$ & $318 \pm 152$ & 0.392 \\
\hline Blood loss (g) & 50 [0-1100] & $148[0-4177]$ & 0.300 \\
\hline Intraoperative blood transfusion & 2 & 6 & 0.178 \\
\hline \multicolumn{4}{|l|}{${ }^{*} p<0.05$} \\
\hline
\end{tabular}

\section{Discussion}

Several reports have analyzed risk factors for SSI after different surgical approaches for patients with different diseases. In orthopedic surgery, many reports regarding risk factors for SSI have been published because of its need for a specifically clean procedure [15-18]. On the other hand, in gastroenterology there has been extensive analysis of risk factors and prevention of SSI in colorectal surgery because of its high rate of SSI occurrence. However, thus far no reports have focused on the risk factors for SSI in all forms of gastroenterological surgery to treat malignancy. 
We found that postoperative hyperglycemia was the sole independent risk factor for incisional SSI, with no other clinical and perioperative factors influencing the occurrence of SSI. Although there is ample evidence showing that perioperative hyperglycemia has been associated with postoperative infective complications, these studies analyzed all infectious disease including SSI, pneumonia, and urinary tract infections [19-21]. Previous reports that focused on the association between postoperative hyperglycemia and the SSI rate highlighted specific surgical procedures, such as colorectal surgery, cardiothoracic surgery, and sleeve gastrectomy $[10,11,22]$. On the other hand, Ata et al. analyzed a total of 2,090 general and vascular surgery patients in whom only the postoperative serum glucose level was associated with SSI [12]. Although this result was consistent with our present findings, the study included a diverse array of surgeries for many diseases, clean or dirty, benign or malignant, as well as gastroenterological or cardiovascular. Our study selected patients with the common circumstance of gastroenterological malignancy, and we considered that this inclusion criterion was reasonable for the improvement of postoperative wound management, which is performed by doctors and nurses in the same department.

In the present study, patients with colorectal malignancy were exclusively analyzed as a subgroup in addition to the analysis of all patients with gastroenterological malignancy. Although the subgroup result was slightly different of that of all study patients, open surgery was also the principal risk factor for incisional SSI. One could theorize that especially in open colorectal surgery, the longer incision on the skin will be more prone to intraoperative contamination by fecal ascites in comparison with laparoscopic surgery. Although several previous studies have analyzed patients who underwent elective colorectal surgery, they have not focused on the postoperative serum blood glucose level, preferring to evaluate the presence or absence of diabetes [23-25]. Thus, the results of our subgroup analysis should be of further value for the prevention of SSI after colorectal surgery.

Unfortunately, in our retrospective study the data on intraoperative body temperature were not available and we were unable to conduct a detailed analysis of the correlation between this factor and SSI occurrence. The guidelines for safe surgery published by the World Health Organization describe that "maintenance of normothermia during surgery" reduces the rate of SSI [26]. Reports have proved the association between intraoperative hypothermia and the incidence of SSI [27, 28]. Tsuchida et al. reported that severe hypothermia $\left(<35.0^{\circ} \mathrm{C}\right)$ and late-nadir hypothermia $\left(<36^{\circ} \mathrm{C}\right.$ more than $2 \mathrm{~h}$ after anesthesia induction) were significant risk factors for SSI in prolonged gastroenterological surgery [27]. On the other hand, contrasting results were also reported in some studies [29,30], and the appropriate intraoperative body temperature remains a controversial aspect. Further study of the impact of intraoperative hypothermia on SSI is therefore warranted.

One of the measures to reduce SSIs is to build the preventive SSI care bundle (i.e., the use of systematic approaches). Many reports have indicated the effectiveness of bundles, especially for colorectal surgery [31, 32]. Some bundles include strict glycemic control [33-35]. Recently in our hospital we have adopted the statute that all severely diabetic patients should be admitted more than 1 week before the operation and should receive specific management of blood glucose level by diabetic physicians to reduce potential 
perioperative complications caused by hyperglycemia. The results reported herein are important in that they indicate the importance of postoperative management of blood glucose levels, not only for severely diabetic patients but for all patients with gastroenterological malignancy.

Our study has several limitations. First, the study was conducted at a single center and was based on a small number of patients. A large-scale multicenter study is needed to confirm our findings. Second, operative and postoperative management involving the types of sutures or dressings and antibiotics used perioperatively were dependent on different clinicians, resulting in an inconsistent quality of care. Finally, other factors not included in our analysis may influence eventual outcomes.

\section{Conclusions}

Postoperative hyperglycemia was the independent risk factor for incisional SSI after surgery for gastroenterological malignancy. Prevention of postoperative hyperglycemia is therefore important in achieving a decrease in the rate of incisional SSI.

\section{Abbreviations}

SSI; surgical site infections

\section{Declarations}

Ethics approval and consent to participate: All study participants provided informed consent, and the study design was approved by the ethics review board of Kitano Hospital (reference no. 2201013). The study was performed in accordance with the Declaration of Helsinki.

Consent for publication: Not applicable

Availability of data and materials: The datasets generated and/or analysed during the current study are not publicly available because individual privacy could be compromised but are available from the corresponding author as a hyperlink to the deposited file on reasonable request.

Competing interests: The authors declare that they have no competing interests.

Funding: The authors declare that they have no funding on this study.

Authors' contributions: TY designed the study. TY and MY acquired the data, TY analyzed and interpreted the data, drafted and revised the manuscript. SU and HT helped to revise the manuscript. All authors read and approved the final version of manuscript.

Acknowledgements: Not applicable

\section{References}


1. Zimlichman E, Henderson D, Tamir O, Franz C, Song P, Yamin CK, Keohane C, Denham CR, Bates DW: Health care-associated infections: a meta-analysis of costs and financial impact on the US health care system. JAMA Intern Med 2013, 173(22):2039-2046.

2. Olson MM, Lee JT, Jr.: Continuous, 10-year wound infection surveillance. Results, advantages, and unanswered questions. Arch Surg 1990, 125(6):794-803.

3. Cruse PJ, Foord R: The epidemiology of wound infection. A 10-year prospective study of 62,939 wounds. Surg Clin North Am 1980, 60(1):27-40.

4. Mahmoud NN, Turpin RS, Yang G, Saunders WB: Impact of surgical site infections on length of stay and costs in selected colorectal procedures. Surg Infect (Larchmt) 2009, 10(6):539-544.

5. Reilly J, Twaddle S, Mclntosh J, Kean L: An economic analysis of surgical wound infection. J Hosp Infect 2001, 49(4):245-249.

6. Pessaux P, Atallah D, Lermite E, Msika S, Hay JM, Flamant Y, Arnaud JP, French Associations for Surgical Research A, Colombes F: Risk factors for prediction of surgical site infections in "clean surgery". Am J Infect Control 2005, 33(5):292-298.

7. Pessaux P, Msika S, Atalla D, Hay JM, Flamant Y, French Association for Surgical R: Risk factors for postoperative infectious complications in noncolorectal abdominal surgery: a multivariate analysis based on a prospective multicenter study of 4718 patients. Arch Surg 2003, 138(3):314-324.

8. Walz JM, Paterson CA, Seligowski JM, Heard SO: Surgical site infection following bowel surgery: a retrospective analysis of 1446 patients. Arch Surg 2006, 141(10):1014-1018; discussion 1018.

9. Martin ET, Kaye KS, Knott C, Nguyen H, Santarossa M, Evans R, Bertran E, Jaber L: Diabetes and Risk of Surgical Site Infection: A Systematic Review and Meta-analysis. Infect Control Hosp Epidemiol 2016, 37(1):88-99.

10. Nakamura T, Sato T, Takayama Y, Naito M, Yamanashi T, Miura H, Atsuko T, Yamashita K, Watanabe M: Risk Factors for Surgical Site Infection after Laparoscopic Surgery for Colon Cancer. Surg Infect (Larchmt) 2016, 17(4):454-458.

11. Latham R, Lancaster AD, Covington JF, Pirolo JS, Thomas CS, Jr.: The association of diabetes and glucose control with surgical-site infections among cardiothoracic surgery patients. Infect Control Hosp Epidemiol 2001, 22(10):607-612.

12. Ata A, Lee J, Bestle SL, Desemone J, Stain SC: Postoperative hyperglycemia and surgical site infection in general surgery patients. Arch Surg 2010, 145(9):858-864.

13. Horan TC, Gaynes RP, Martone WJ, Jarvis WR, Emori TG: CDC definitions of nosocomial surgical site infections, 1992: a modification of CDC definitions of surgical wound infections. Infect Control Hosp Epidemiol 1992, 13(10):606-608.

14. Berrios-Torres SI, Umscheid CA, Bratzler DW, Leas B, Stone EC, Kelz RR, Reinke CE, Morgan S, Solomkin JS, Mazuski JE et al: Centers for Disease Control and Prevention Guideline for the Prevention of Surgical Site Infection, 2017. JAMA Surg 2017, 152(8):784-791.

15. Pulido L, Ghanem E, Joshi A, Purtill JJ, Parvizi J: Periprosthetic joint infection: the incidence, timing, and predisposing factors. Clin Orthop Relat Res 2008, 466(7):1710-1715. 
16. Malinzak RA, Ritter MA, Berend ME, Meding JB, Olberding EM, Davis KE: Morbidly obese, diabetic, younger, and unilateral joint arthroplasty patients have elevated total joint arthroplasty infection rates. J Arthroplasty 2009, 24(6 Suppl):84-88.

17. Marchant MH, Jr., Viens NA, Cook C, Vail TP, Bolognesi MP: The impact of glycemic control and diabetes mellitus on perioperative outcomes after total joint arthroplasty. J Bone Joint Surg Am 2009, 91(7):1621-1629.

18. Jamsen E, Huhtala H, Puolakka T, Moilanen T: Risk factors for infection after knee arthroplasty. A register-based analysis of 43,149 cases. J Bone Joint Surg Am 2009, 91(1):38-47.

19. King JT, Jr., Goulet JL, Perkal MF, Rosenthal RA: Glycemic control and infections in patients with diabetes undergoing noncardiac surgery. Ann Surg 2011, 253(1):158-165.

20. Frisch A, Chandra P, Smiley D, Peng L, Rizzo M, Gatcliffe C, Hudson M, Mendoza J, Johnson R, Lin E et al: Prevalence and clinical outcome of hyperglycemia in the perioperative period in noncardiac surgery. Diabetes Care 2010, 33(8):1783-1788.

21. Umpierrez GE, Smiley D, Jacobs S, Peng L, Temponi A, Mulligan P, Umpierrez D, Newton C, Olson D, Rizzo M: Randomized study of basal-bolus insulin therapy in the inpatient management of patients with type 2 diabetes undergoing general surgery (RABBIT 2 surgery). Diabetes Care 2011, 34(2):256261.

22. Ruiz-Tovar J, Oller I, Llavero C, Arroyo A, Munoz JL, Calero A, Diez M, Zubiaga L, Calpena R: Preoperative and early post-operative factors associated with surgical site infection after laparoscopic sleeve gastrectomy. Surg Infect (Larchmt) 2013, 14(4):369-373.

23. Smith RL, Bohl JK, McElearney ST, Friel CM, Barclay MM, Sawyer RG, Foley EF: Wound infection after elective colorectal resection. Ann Surg 2004, 239(5):599-605; discussion 605-597.

24. Konishi T, Watanabe T, Kishimoto J, Nagawa $\mathrm{H}$ : Elective colon and rectal surgery differ in risk factors for wound infection: results of prospective surveillance. Ann Surg 2006, 244(5):758-763.

25. Bullard KM, Trudel JL, Baxter NN, Rothenberger DA: Primary perineal wound closure after preoperative radiotherapy and abdominoperineal resection has a high incidence of wound failure. Dis Colon Rectum 2005, 48(3):438-443.

26. 26.. In: WHO Guidelines for Safe Surgery 2009: Safe Surgery Saves Lives. edn. Geneva; 2009.

27. Tsuchida T, Takesue Y, Ichiki K, Uede T, Nakajima K, Ikeuchi H, Uchino M: Influence of Peri-Operative Hypothermia on Surgical Site Infection in Prolonged Gastroenterological Surgery. Surg Infect (Larchmt) 2016, 17(5):570-576.

28. Kurz A, Sessler DI, Lenhardt R: Perioperative normothermia to reduce the incidence of surgical-wound infection and shorten hospitalization. Study of Wound Infection and Temperature Group. N Engl J Med 1996, 334(19):1209-1215.

29. Baucom RB, Phillips SE, Ehrenfeld JM, Muldoon RL, Poulose BK, Herline AJ, Wise PE, Geiger TM: Association of Perioperative Hypothermia During Colectomy With Surgical Site Infection. JAMA Surg 2015, 150(6):570-575. 
30. Brown MJ, Curry TB, Hyder JA, Berbari EF, Truty MJ, Schroeder DR, Hanson AC, Kor DJ: Intraoperative Hypothermia and Surgical Site Infections in Patients with Class I/Clean Wounds: A Case-Control Study. J Am Coll Surg 2017, 224(2):160-171.

31. Tanner J, Padley W, Assadian O, Leaper D, Kiernan M, Edmiston C: Do surgical care bundles reduce the risk of surgical site infections in patients undergoing colorectal surgery? A systematic review and cohort meta-analysis of 8,515 patients. Surgery 2015, 158(1):66-77.

32. Yamamoto T, Morimoto T, Kita R, Masui H, Kinoshita H, Sakamoto Y, Okada K, Komori J, Miki A, Kondo $\mathrm{M}$ et al: The preventive surgical site infection bundle in patients with colorectal perforation. BMC Surg 2015, 15:128.

33. Keenan JE, Speicher PJ, Thacker JK, Walter M, Kuchibhatla M, Mantyh CR: The preventive surgical site infection bundle in colorectal surgery: an effective approach to surgical site infection reduction and health care cost savings. JAMA Surg 2014, 149(10):1045-1052.

34. Lutfiyya W, Parsons D, Breen J: A colorectal "care bundle" to reduce surgical site infections in colorectal surgeries: a single-center experience. Perm J 2012, 16(3):10-16.

35. Waits SA, Fritze D, Banerjee M, Zhang W, Kubus J, Englesbe MJ, Campbell DA, Jr., Hendren S: Developing an argument for bundled interventions to reduce surgical site infection in colorectal surgery. Surgery 2014, 155(4):602-606.

\section{Figures}

Fig. 1

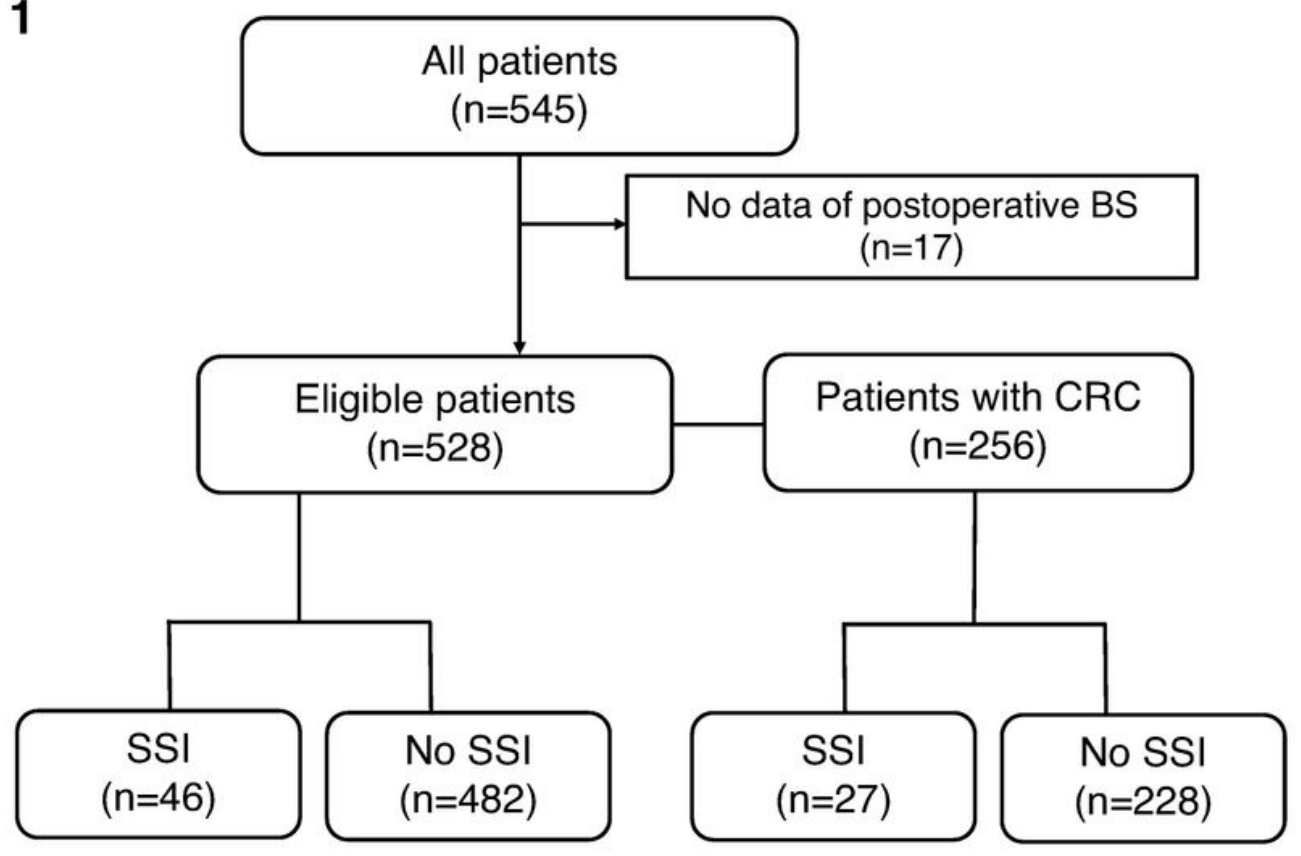

Figure 1 
Patient selection

Page 15/15 